
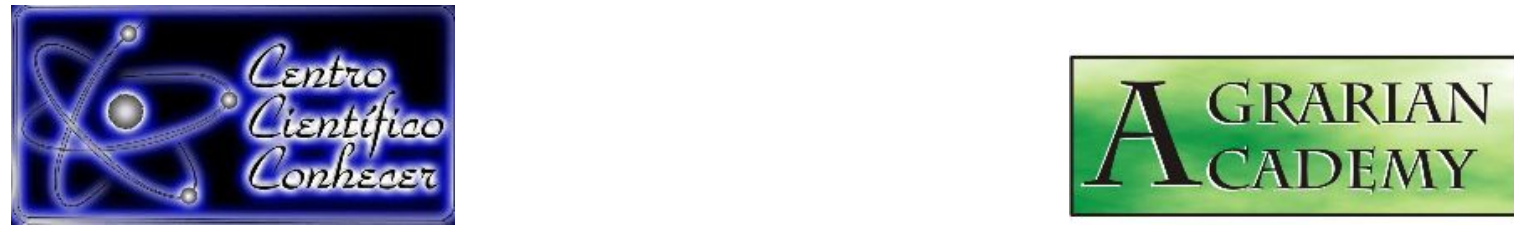

\title{
EFEITO DE DIFERENTES CONCENTRAÇÕES DE AIB NA PROPAGAÇÃO POR ESTAQUIA DE TABERNAEMONTANA DIVARICATA (L.)
}

Andressa Fabiane Faria de Souza ${ }^{1}$, Eduardo Carvalho da Silva Neto ${ }^{2}$, Marcondes Geraldo Coelho Júnior ${ }^{3}$, Janne Kety de Sousa Nogueira ${ }^{4}$, Ana Amélia dos Santos Cordeiro ${ }^{5}$

${ }^{1}$ Doutoranda em Agronomia/Ciência do Solo, Universidade Federal Rural do Rio de Janeiro (UFRRJ), Seropédica/RJ, Brasil, affariasouza@gmail.com

${ }^{2}$ Doutorando em Agronomia/Ciência do Solo, UFRRJ

${ }^{3}$ Mestrando em Ciências Ambientais e Florestais, UFRRJ

${ }^{4}$ Engenheira Agrônoma, UFRRJ

${ }^{5}$ Professora no Instituto Federal do Norte de Minas, Campus Arinos/MG

Recebido em: 14/07/2018 - Aprovado em: 28/07/2018 - Publicado em: 31/07/2018

DOI: 10.18677/Agrarian_Academy_2018a21

\section{RESUMO}

A espécie Tabernaemontana divaricata (família Apocynaceae), planta arbustiva conhecida vulgarmente por jasmim-café, possui um grande destaque na medicina popular, atraindo a atenção da comunidade científica para novos estudos. O objetivo deste trabalho foi analisar a formação de calo, raiz, e brotação em estacas de Tabernaemontana divaricata (L). em diferentes concentrações de ácido indolbutírico (AIB) (0, 2000, 4000 e 6000 ppm). As estacas lenhosas apresentaram maiores valores percentuais na formação de calo, raiz e brotação. Quanto ao efeito das concentrações de AIB, o tratamento de $2000 \mathrm{mg}^{-1} \mathrm{~L}^{-1}$ apresentou os maiores valores, demonstrando ser este o tratamento mais indicado para a espécie avaliada.

PALAVRAS-CHAVE: AIB (ácido indolbutírico), propagação por estaquia, Tabernaemontana divaricata (L.).

\section{EFFECT OF DIFFERENT CONCENTRATIONS OF IBA ON PROPAGATION BY CUTTINGS OF TABERNAEMONTANA DIVARICATA (L.)}

\section{ABSTRACT}

The species Tabernaemontana divaricata (family Apocynaceae), ornamental bush is commonly known as crape jasmine, has a great prominence in folk medicine, attracting the attention of the scientific community to new studies. The aim of this work was to analyze the formation of callus, root, and sprouting in cuttings of Tabernaemontana divaricata (L). in different concentrations of indolebutyric acid (IBA) (0, 2000, 4000 and 6000 ppm). The woody cuttings presented higher percentage values in the formation of callus, root, and sprouting. As for the effect of AIB concentrations, the $2000 \mathrm{mg} . \mathrm{L}^{-1}$ treatment presented the highest values, showing that this treatment is the most appropriate treatment for the evaluated species.

KEYWORDS: IBA (indolebutyric acid); propagation by cuttings; Tabernaemontana divaricata (L.).

AGRARIAN ACADEMY, Centro Científico Conhecer - Goiânia, v.5, n.9; p. 2042018 


\section{INTRODUÇÃo}

O gênero Tabernaemontana pertence à família Apocynaceae, e inclui cerca de 110 espécies que se distribuem principalmente nas áreas tropicais e subtropicais da Ásia, Oceania, África e Américas (SIMÕES et al., 2010; BAO et al., 2013). No Brasil são reconhecidas 30 espécies do gênero, sendo nove endêmicas (KOCH et al., 2015). A espécie Tabernaemontana divaricata, conhecida vulgarmente por jasmim-café, é encontrada principalmente em áreas de Mata Atlântica do Estado de Pernambuco (MARINHO et al., 2016).

A espécie se apresenta como um arbusto perene, se desenvolve em campos selvagens ou em florestas, podendo também ser cultivada como planta ornamental (KUMAR; SELVAKUMAR, 2015; ALI KHAN et al., 2018). De acordo com o International Plant Names Index (IPNI, 2015) a espécie Tabernaemontana divaricata (L.) possui cerca de 23 sinônimos, dentre eles Ervatamia coronaria (Jacq.) Stapf, Ervatamia divaricata (L.) Burkill, Nerium coronarium Jacq., Tabernaemontana coronaria (Jacq.) Willd., sendo sinônimos importantes na identificação da espécie.

$T$. divaricata possui um grande destaque na medicina popular por ser uma fonte rica de vários tipos de alcaloides facilmente extraídos do látex ou das cascas do caule pelo processo de infusão (CHANCHAL et al., 2015; MARINHO et al., 2016). O seu uso já foi relatado como analgésico, anti-inflamatório, antioxidante, antiinfecção, antitumoral, usada no tratamento de dores abdominais, epilepsia, dor de garganta, no tratamento de fertilidade, e dores reumáticas (KUMAR; SELVAKUMAR, 2015). Devido a sua importância medicinal, esta espécie tem atraído a atenção da comunidade científica para estudos de novos ingredientes ativos e o efeito farmacológico de cada molécula isolada (BAO et al., 2013; CHANCHAL et al., 2015; MARINHO et al., 2016; ALI KHAN et al., 2018). Apesar do crescente interesse no uso desses compostos poucos são os estudos até o momento da propagação vegetativa, técnica que utiliza caules, raízes ou folhas para a confecção de estacas em que objetivo principal é preservar as características encontradas na planta mãe no novo indivíduo (PIMENTA et al., 2017).

Aliado a propagação vegetativa por estaquia está o uso de reguladores vegetais, que promovem maior enraizamento das espécies, aumenta a produção de mudas em menor espaço de tempo, maior número e maior vigor das raízes, além de aumentar a uniformidade do enraizamento (XAVIER et al., 2013). Entre os reguladores de crescimento, as auxinas são as empregadas com maior frequência (LIMA et al., 2016). O ácido indolbutírico (AIB), uma auxina sintética, mais estável e menos solúvel que a auxina endógena, é considerado um dos melhores estimuladores do enraizamento, e não é tóxico para a maioria das plantas, mesmo em doses elevadas (RIOS et al., 2012).

Tendo em vista a escassez de trabalhos na literatura acerca da propagação dessa espécie, bem como os efeitos da auxina sobre o enraizamento, o presente trabalho teve como objetivo analisar a formação de calo, raiz e brotação em estacas de Tabernaemontana divaricata (L). em diferentes concentrações de ácido indolbutírico.

\section{MATERIAL E MÉTODOS}

O experimento foi conduzido em casa de vegetação, no Departamento de Fitotecnia da Universidade Federal Rural do Rio de Janeiro (UFRRJ), município de Seropédica - RJ. O clima da região é classificado como Cwa segundo Köppen, com inverno moderadamente frio e verão quente, com precipitação média anual de 1280 mm e temperatura média anual de $22,5^{\circ} \mathrm{C}$.

AGRARIAN ACADEMY, Centro Científico Conhecer - Goiânia, v.5, n.9; p. 2052018 
As estacas foram coletadas de plantas do campus da universidade, com aproximadamente três anos de idade. Foram selecionados aleatoriamente ramos sadios dos quais se obteve três tipos de estacas em relação ao estádio de desenvolvimento: estacas herbáceas (subapicais, com $\pm 0,50-0,80 \mathrm{~cm}$ de diâmetro), estacas semilenhosas (terço mediano, com $\pm 0,80-1,0 \mathrm{~cm}$ de diâmetro) e estacas lenhosas (terço basal, $\pm 1,0$ cm de diâmetro).

As folhas foram retiradas com cuidado, para não danificar as gemas. Todas as estacas foram cortadas em bisel, com $15 \mathrm{~cm}$ de comprimento, e imersas em solução do fungicida Benomyl a 0,2\%, durante 10 segundos. As soluções foram preparadas por meio da dissolução de AIB em álcool $50 \%$ para a obtenção das respectivas concentrações.

Para o tratamento com ácido indolbutírico (AIB), as estacas foram colocadas com a base na solução-tratamento $(0,2000,4000$ e 6000 ppm) por 10 segundos, sendo posteriormente plantadas em canteiros contendo areia lavada, sob sistema de irrigação com nebulização intermitente. Transcorridos 40 dias após a instalação do experimento, as estacas foram arrancadas e avaliadas quanto ao aparecimento ou não de calos, raízes e brotações.

O delineamento estatístico adotado foi o de blocos ao acaso (dentro de cada bloco, os tratamentos são dispostos ao acaso) com três repetições e 10 estacas por parcelas (Figura 1). A principal vantagem deste delineamento é que parte da variação experimental é extraída do erro e colocada na repetição. A análise do experimento foi em esquema fatorial $3 \times 3$ (três tipos de estacas e três concentrações de AIB). Os dados obtidos foram submetidos a análise de variância através do teste de normalidade (teste de Shapiro-Wilk), homogeneidade das variâncias (teste de Bartlett), e os valores médios comparados entre si pelo teste Scott-Knott a $5 \%$ de probabilidade ( $p$-value $<0,05$ ). Os efeitos das variáveis foram verificados pelo teste $\mathrm{F}$ ( $5 \%$ de probabilidade).

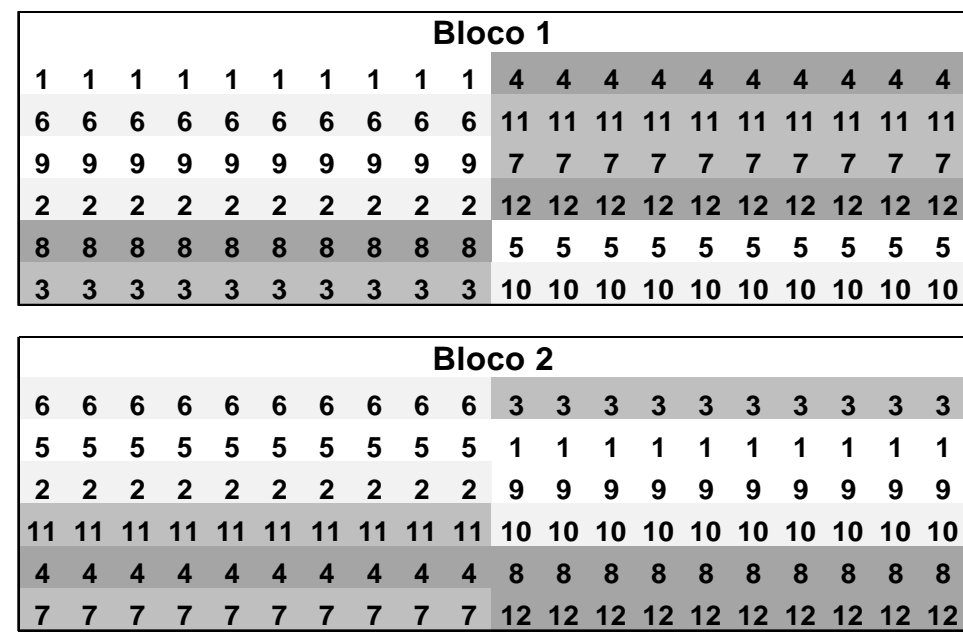

\begin{tabular}{|cccccccccccccccccccc|}
\hline \multicolumn{11}{c|}{ Bloco 3} \\
\hline 7 & 7 & 7 & 7 & 7 & 7 & 7 & 7 & 7 & 7 & 8 & 8 & 8 & 8 & 8 & 8 & 8 & 8 & 8 & 8 \\
9 & 9 & 9 & 9 & 9 & 9 & 9 & 9 & 9 & 9 & 6 & 6 & 6 & 6 & 6 & 6 & 6 & 6 & 6 & 6 \\
12 & 12 & 12 & 12 & 12 & 12 & 12 & 12 & 12 & 12 & 10 & 10 & 10 & 10 & 10 & 10 & 10 & 10 & 10 & 10 \\
3 & 3 & 3 & 3 & 3 & 3 & 3 & 3 & 3 & 3 & 4 & 4 & 4 & 4 & 4 & 4 & 4 & 4 & 4 & 4 \\
1 & 1 & 1 & 1 & 1 & 1 & 1 & 1 & 1 & 1 & 5 & 5 & 5 & 5 & 5 & 5 & 5 & 5 & 5 & 5 \\
2 & 2 & 2 & 2 & 2 & 2 & 2 & 2 & 2 & 2 & 11 & 11 & 11 & 11 & 11 & 11 & 11 & 11 & 11 & 11 \\
\hline
\end{tabular}

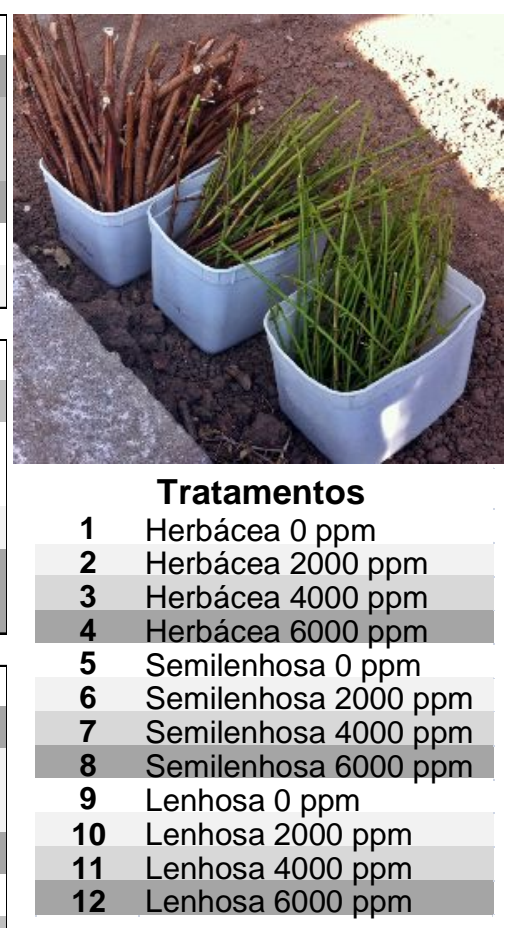

FIGURA 1. Delineamento experimental adotado de blocos ao acaso, com três repetições e 10 estacas por parcelas $(n=360)$. Tratamento com ácido indolbutírico (AIB) em função das diferentes concentrações (0, 2000, 4000 e 6000 ppm) e dos tipos de estaca (herbáceas, semilenhosas e lenhosas). 


\section{RESULTADOS E DISCUSSÃo}

Foram observadas diferenças significativas para a formação de calo, raiz e brotação entre os tipos de estacas e doses de AIB (Tabela 1). A formação de tecido caloso foi maior nas estacas lenhosas em todas as concentrações de AIB, de forma semelhante aos resultados obtidos por Loss et al. (2008; 2009), em estudos semelhantes com Allamanda cathartica L. e Malvaviscus arboreus Cav., respectivamente, ambas tratadas com AIB em diferentes concentrações.

Nas estacas semilenhosas e lenhosas, a concentração de $2000 \mathrm{mg} \mathrm{L}^{-1}$ de AIB foi a mais eficiente no estímulo da formação de tecido caloso, sendo as doses 4000 e $6000 \mathrm{mg} \mathrm{L}^{-1}$ de AIB, estatiscamente inferiores, semelhantes às testemunhas. Para as estacas herbáceas, não foram observadas diferenças significativas com o aumento da dose de AIB, sendo também a concentração $2000 \mathrm{mg} \mathrm{L}^{-1}$ de AIB a mais indicada.

TABELA 1. Efeito da interação dos diferentes tipos de estaca e concentrações de Ácido Indolbutírico (AIB) em relação ao percentual de formação de calo, raiz e brotação em Tabernaemontana divaricata, conduzido na UFRRJ, Seropédica - RJ.

\begin{tabular}{|c|c|c|c|c|}
\hline \multirow[b]{2}{*}{$\begin{array}{l}\text { Variáveis } \\
\text { analisadas }\end{array}$} & \multirow[b]{2}{*}{$\begin{array}{c}\text { Concentração } \\
\mathrm{mg} \mathrm{L}^{-1}\end{array}$} & \multicolumn{3}{|c|}{ Tipos de estacas } \\
\hline & & Herbácea & Semilenhosa & Lenhosa \\
\hline \multirow{4}{*}{ Calo } & 0 & $13,2 \mathrm{Bb}$ & $18,5 \mathrm{Bb}$ & $26,3 \mathrm{Ca}$ \\
\hline & 2000 & $28,6 \mathrm{Ab}$ & $31,0 A b$ & $41,6 \mathrm{Aa}$ \\
\hline & 4000 & $27,6 \mathrm{Ab}$ & $24,3 \mathrm{Bb}$ & $33,7 \mathrm{Ba}$ \\
\hline & 6000 & $25,2 A b$ & $20,7 \mathrm{Bb}$ & $27,3 \mathrm{Ba}$ \\
\hline \multirow{4}{*}{ Raiz } & 0 & $21,6 \mathrm{Bb}$ & $26,4 \mathrm{Bb}$ & $31,8 \mathrm{Ba}$ \\
\hline & 2000 & $26,7 \mathrm{Ab}$ & $32,5 \mathrm{Ab}$ & $44,6 \mathrm{Aa}$ \\
\hline & 4000 & $25,9 A b$ & $24,1 \mathrm{Bb}$ & $32,3 \mathrm{Ba}$ \\
\hline & 6000 & $20,9 \mathrm{Bb}$ & $24,3 \mathrm{Bb}$ & $32,0 \mathrm{Ba}$ \\
\hline \multirow{4}{*}{ Brotação } & 0 & $23,2 \mathrm{Bb}$ & $26,9 \mathrm{Db}$ & 33,6Ca \\
\hline & 2000 & $35,7 \mathrm{Ab}$ & $45,8 \mathrm{Aa}$ & $51,1 \mathrm{Aa}$ \\
\hline & 4000 & $31,4 \mathrm{Ab}$ & $39,7 \mathrm{Ba}$ & $43,8 \mathrm{Ba}$ \\
\hline & 6000 & $26,7 \mathrm{Bb}$ & $33,4 \mathrm{Ca}$ & $34,2 \mathrm{Ca}$ \\
\hline
\end{tabular}

Médias seguidas de mesma letra maiúscula na coluna não diferem significativamente entre as concentrações, para cada tipo de estaca, pelo teste de Scott-Knott a 5\%; seguidas pela mesma letra minúscula na linha não diferem entre os tipos de estacas, para cada concentração, pelo teste Scott-Knott a 5\% de probabilidade ( $p$-value $<0,05$ ).

Rawat et al. (2014), em estudo com a mesma espécie (Tabernaemontana divaricata) avaliando o efeito dos métodos de aplicação e diferentes concentrações de AIB na formação de calo, raiz e brotação, observaram maiores valores para a menor concentração de AIB testada (3000 $\left.\mathrm{mg} \mathrm{L}^{-1}\right)$. De acordo com Taiz et al. (2016) as auxinas sintéticas induzem ao alongamento celular e alteram as atividades fisiológicas da planta, e dependendo da concentração, inibe ou estimula o crescimento e a diferenciação dos tecidos, existindo um nível ótimo para estas respostas fisiológicas, o que está diretamente relacionado aos níveis endógenos dessas substâncias. 
Com relação à formação de raízes, as estacas lenhosas também apresentaram maiores valores percentuais. O melhor desempenho para esse parâmetro foi observado na concentração de $2000 \mathrm{mg} \mathrm{L}^{-1}$, seguindo o mesmo padrão da formação de tecido caloso. As estacas herbáceas apresentaram as menores médias, sendo a dose de $2000 \mathrm{mg} \mathrm{L}^{-1}$ a mais eficiente, uma vez que, aumentando a concentração de AIB para $4000 \mathrm{mg} \mathrm{L}^{-1}$, não se observa resposta significativa, e na concentração de $6000 \mathrm{mg} \mathrm{L}^{-1}$, observa-se média estatisticamente inferior. Ataíde et al. (2017), ao estudarem a propagação vegetativa de estaquia de umbuzeiro (Spondias tuberosa Arruda) no estádio reprodutivo sob diferentes concentrações de AIB $\left(0,3000,6000\right.$ e $\left.9.000 \mathrm{mg} \mathrm{L}^{-1}\right)$, puderam inferir que o uso de AIB nas doses e concentrações utilizadas não promoveu enraizamento e brotações satisfatórias das estacas de umbuzeiros.

Em trabalho conduzido por Oliveira et al. (2011), verificou-se que a maior taxa de enraizamento em estacas de Hyptis leucocephala e Hyptis platanifolia foi obtida com 2000 e $4000 \mathrm{mg} \mathrm{L}^{-1}$ de AIB. Chowdhuri et al. (2017) ao estudarem a propagação vegetativa de estaquia em Tabernaemontana divaricata com estacas semilenhosas em diferentes concentrações de AIB (1000, 2000 e 3000 ppm), observaram maior enraizamento, comprimento radicular, e percentual de sobrevivência das estacas na concentração de 3000 ppm de AIB. Em trabalho conduzido por Pereira et al. (2015), verificou-se que a maior taxa de enraizamento em estacas de Tibouchina moricandiana var vinacea foi obtida com $2000 \mathrm{mg} \mathrm{L}^{-1}$ de AIB.

As auxinas são os reguladores vegetais com maior efetividade na promoção do enraizamento (XAVIER et al., 2013), entretanto, a concentração hormonal necessária é variável para cada espécie e o tipo de regulador tem resposta diferente devido às raízes serem muito sensíveis a essas substâncias e qualquer acréscimo, além do necessário, pode tornar-se inibitório à formação de raízes adventícias (CUNHA et al., 2012).

A porcentagem de brotação apresentou comportamento diferenciado dos demais parâmetros avaliados, não apresentando diferença significativa entre as estacas semilenhosas e lenhosas tratadas com AIB, independente da concentração. As estacas herbáceas, menos lignificadas, assim como para a formação de calos e raízes, também apresentaram as menores médias.

Cabe ressaltar que a propagação via estaquia, utilizando AIB como indutor de enraizamento, responde a outras variáveis que não apenas a concentração desta auxina sintética ou a época de coleta das estacas, como também as características morfofisiológicas intrínsecas das espécies utilizadas, dado a sua taxonomia e relações sistemático-filogenéticas (PEREIRA et al., 2012).

\section{CONCLUSÃO}

O tratamento de estacas de jasmim-café (Tabernaemontana divaricata) com ácido indolbutírico nas concentrações de 2000 e 4000 ppm aumenta a formação de calo, raiz e brotação. A estaca lenhosa apresentou os melhores resultados para a formação de tecido caloso, enraizamento e brotação.

Quanto ao efeito das concentrações de AIB, o tratamento de $2000 \mathrm{mg} \mathrm{L}-1$ apresentou os maiores valores, demonstrando ser este o tratamento mais indicado para a espécie avaliada. O AIB pode ser utilizado como indutor do enraizamento em estacas de Tabernaemontana divaricata. 


\section{REFERÊNCIAS}

ATAÍDE, E. M.; SILVA, M. S.; SOUZA, J. M. A.; BASTOS, D. C. Ácido indolbutírico e substratos no desenvolvimento de estacas de umbuzeiro em três estádios fenológicos. Agrarian Academy, v. 4, n. 8, p. 21-33, 2017. Disponível em: <http://www.conhecer.org.br/Agrarian\%20Academy/2017b/acido\%20indolbutirico.pdf >. doi: 10.18677/Agrarian_Academy_2017b3.

ALI KHAN, M. S.; MISBAH; AHMED, N.; ARIFUDDIN, M.; REHMAN, A.; LING, M. P. Indole alkaloids and anti-nociceptive mechanisms of Tabernaemontana divaricata (L.) R. Br. flower methanolic extract. Food and Chemical Toxicology, Epub ahead of print, 2018.2 Disponível em: <https://www.sciencedirect.com/science/article/pii/S0278691518303818?via\%3Dihub >. doi: $10.1016 /$ j.fct.2018.06.007.

BAO, M-F.; YAN, J. M.; CHENG, G. G.; LI, X. Y.; LIU, Y. P.; LI, Y.; CAI, X. H.; LUO, $X$. D. Cytotoxic indole alkaloids from Tabernaemontana divaricata. Journal of Natural Products, v. 76, n. 8, p. 1406-1412, 2013. Disponível em: $<$ https://pubs.acs.org/doi/pdf/10.1021/np400130y>. doi: 10.1021/np400130y.

CHANCHAL, R.; BALASUBRAMANIAM, A.; NAVIN, R.; NADEEM, S. Tabernaemontana divaricata leaves extract exacerbate burying behavior in mice. Avicenna Journal of Phytomedicine, v. 5, n. 4, p. 282-287, 2015. Disponível em: <https://www.ncbi.nlm.nih.gov/pmc/articles/PMC4587605/>. PMC4587605.

CHOWDHURI, T. K.; SADHUKHAN, R.; MONDAL, T.; DAS, S. Effect of different growth regulators on propagation of Cape jasmine (Tabernaemontana coronaria var. Dwarf) in subtropical zone of West Bengal. The Asian Journal of Horticulture, v. 12, n. 2, p. 206-210, 2017. Disponível em: <http://www.researchjournal.co.in/online/TAJH/TAJH-12-2-2017.htm>. 10.15740/HAS/TAJH/12.2/206-210.

CUNHA, C. S. M.; MAIA, S. S S.; COELHO, M. F. B. Estaquia de Croton zehntneri Pax et Hoffm. com diferentes concentrações de ácido indolbutírico. Ciência Rural, v. 42, n. $\quad 4, \quad$ p. 621-626, 2012. Disponível em: <http://www.redalyc.org/articulo.oa?id=33122470007 . ISSN 0103-8478.

IPNI - INTERNATIONAL PLANT NAMES INDEX. Tabernaemontana divaricata (L.), 2015. Disponível em: <http://www.ipni.org/>. Acesso em: 05 Jul. 2018.

KOCH, I.; RAPINI, A.; SIMÕES, A. O.; KINOSHITA, L. S.; SPINA, A. P.; CASTELLO, A. C. D. Apocynaceae em Lista de Espécies da Flora do Brasil. Jardim Botânico do Rio de Janeiro. Flora do Brasil 2020, 2015. Disponível em: $<$ http://floradobrasil.jbrj.gov.br/jabot/floradobrasil/FB4860>. Acesso em 05 Jul. 2018.

KUMAR, A.; SELVAKUMAR, S. Antiproliferative effcacy of Tabernaemontana divaricata against HEP2 cell line and vero cell line. Pharmacognosy Magazine, v. 11, n. 42, p. 46-52, 2015. Disponível em: < http://www.phcog.com/text.asp?2015/11/42/46/157682>. doi: 10.4103/09731296.157682. 
LOSS, A.; TEIXEIRA, M. B.; ASSUNÇÃO, G. M.; HAIM, P. G.; LOUREIRO, D. C.; SOUZA, J. R. Enraizamento de estacas de Allamanda catartica L. tratadas com ácido indolbutírico (AIB). Revista Brasileira de Ciências Agrárias, v. 3, n. 4, p. 313-316, $2008 . \quad$ Disponível em: <http://www.redalyc.org/articulo.oa?id=119017357003>. ISSN 1981-1160.

LOSS, A.; TEIXEIRA, M. B.; SANTOS, T. J.; GOMES, V. M.; QUEIROZ, L. H. Indução do enraizamento em estacas de Malvaviscus arboreus Cav. com diferentes concentrações de ácido indolbutírico (AIB). Acta Scientiarum Agronomy, v. 31, n. 2, p. 269-273, 2009. Disponível em: <http://www.redalyc.org/html/3030/303026587013/>.doi:10.4025/actasciagron.v31i2. 799.

LIMA, D. M.; KLEIN, A. W.; SALLA, V. P.; MOURA, A. P. C.; DANNER, M. A. Ácido indolbutírico no enraizamento de estacas de Langerstroemia indica em diferentes substratos. Pesquisa Florestal Brasileira, v. 36, n. 88, p. 549-554, 2016. Disponível em: $\quad<h t t p s: / / p f b . c n p f . e m b r a p a . b r / p f b / i n d e x . p h p / p f b / a r t i c l e / v i e w / 1022>$. doi: https://doi.org/10.4336/2016.pfb.36.88.1022.

MARINHO, F. F.; SIMÕES, A. O.; BARCELLOS, T.; MOURA, S. Brazilian Tabernaemontana genus: Indole alkaloids and phytochemical activities. Fitoterapia, v. $114, \quad$ p. 127-137, 2016. Disponível em: <http://dx.doi.org/10.1016/j.fitote.2016.09.002 >. doi: 10.1016/j.fitote.2016.09.002.

OLIVEIRA, L. M.; NEPOMUCENO, C. F.; FREITAS, N. P.; PEREIRA, D. M. S.; SILVA, G. C.; LUCCHESE, A. M. Propagação vegetativa de Hyptis leucocephala Mart. ex Benth. e Hyptis platanifolia Mart. ex Benth. (Lamiaceae). Revista Brasileira de Plantas Medicinais, v. 13, n. 1, p. 73-78, 2011. Disponível em: <http://dx.doi.org/10.1590/S1516-05722011000100011>. doi: 10.1590/S151605722011000100011.

PIMENTA, A. C.; AMANO, E.; ZUFFELLATO-RIBAS, K. C. Estaquia e anatomia caulinar de Annona crassiflora Mart. Caderno de Ciências Agrárias, v. 9, n. 2, p. 17, 2017. Disponível em: < https://seer.ufmg.br/index.php/ccaufmg/article/view/4459>. ISSN 2447-6218.

PEREIRA, G. H. A.; COUTINHO, F. S.; COSTA E SILVA, R. A., LOSS, A. Desenvolvimento de estacas de alamanda amarela sob diferentes concentrações de ácido indolbutírico. Comunicata Scientiae, v. 3, n. 1, p. 16-22, 2012. Disponível em: $<$ https://dialnet.unirioja.es/servlet/articulo?codigo=3884755>. ISSN-e 2177-5133.

PEREIRA, M. O; GRABIAS, J.; ZUFFELATTO-RIBAS, K. C.; NAVROSKI, M. C. Enraizamento de estacas de Tibouchina moricandiana var. vinacea em função da forma de aplicação e concentrações de AIB. Revista de Ciências Agroveterinárias, v. $14, \quad$ n. 3 , p. 210-216, $2015 . \quad$ Disponível em:<http://dx.doi.org/10.5965/223811711432015210>.doi:10.5965/22381171143201 5210. 
RAWAT, J. M. S.; SINGH, K. K.; RAWAT, V.; SINGH, B. Effect of methods of IBA application on rooting performance of crape jasmine (Chandani) softwood cuttings. HortFlora Research Spectrum, v. 3, n. 2, p. 146-149, 2014. Disponível em: <https://www.cabdirect.org/cabdirect/abstract/20143412118>. ISSN: 2250-2823.

RIOS, E. S.; PEREIRA, M. C.; SANTOS, L. S.; SOUZA, T. C.; RIBEIRO, V. G. Concentrações de ácido indolbutírico, comprimento e época de coleta de estacas, na propagação de umbuzeiro. Revista Caatinga, v. 25, n. 1, p. 52-57, 2012. Disponível em: <http://www.redalyc.org/articulo.oa?id=237123860008>. ISSN: 1983-2125.

SIMÕES, A. O.; ENDRESS, M. E. E.; CONTI, E. Systematics and character evolution of Tabernaemontaneae (Apocynaceae, Rauvolfioideae) based on molecular and morphological evidence. Taxon, v. 59, n. 3, p. 772-790, 2010. www.jstor.org/stable/25677668. doi: 10.2307/25677668.

TAIZ, L.; ZEIGER, E.; MOLLER, I. M.; MURPHY, A. Fisiologia e desenvolvimento vegetal. 6. ed. Porto Alegre/RS: Editora Artmed, 2016. 888 p.

XAVIER, A.; WENDLING, I.; SILVA, R. L. Silvicultura clonal: princípios e técnicas. 2. ed. Viçosa/MG: Editora UFV, 2013. 279 p. 